\title{
Short Communication: Amino Acid Transporters in Porcine Mammary Gland During Lactation*
}

\author{
J. Pérez Laspiur, ${ }^{1}$ J. L. Burton, ${ }^{1}$ P. S. D. Weber, ${ }^{1}$ \\ R. N. Kirkwood, ${ }^{2}$ and N. L. Trottier ${ }^{1}$ \\ ${ }^{1}$ Department of Animal Science and \\ ${ }^{2}$ College of Veterinary Medicine, \\ Michigan State University, East Lansing 48824
}

\section{ABSTRACT}

The objective of this study was to determine whether mRNA transcripts for the amino acid (AA) transporter proteins CAT-1, CAT-2B, $\mathrm{B}^{0,+}$, and ASCT1 are present in porcine mammary tissue (MT). Transcript abundance on $\mathrm{d} 7$ and 17 of lactation was determined by Northern blot analysis, and absolute quantification was performed by real-time polymerase chain reaction. Porcine MT expresses CAT-1, CAT-2B, $\mathrm{B}^{0,+}$, and ASCT1 during lactation. Preliminary findings indicate that $\mathrm{B}^{0,+} \mathrm{mRNA}$ abundance tended to decrease on d 17 compared with that on $\mathrm{d} 7$.

(Key words: amino acid transporter, mammary gland, lactation, porcine)

\section{Abbreviation key: MT = mammary tissue.}

Despite the central role of AA transporters in the provision of AA necessary for synthesis of proteins for cell structure, enzymes, and signaling mechanisms (Meyer, 2001), little is known about regulation of AA transport and/or the factors that affect their activity in various tissues. Expression of AA transporter transcripts and proteins known to mediate AA transport in other tissues has not been studied in porcine mammary tissue (MT). Such knowledge is critical to enhance our understanding of the factors controlling milk protein synthesis in lactating sows. Kinetic studies using porcine MT explants have provided indirect evidence that AA transport in $\mathrm{MT}$ is specific and carrier-mediated (Jackson et al., 2000; Hurley et al., 2000). This led us to hypothesize that AA transporter proteins CAT-1, CAT-2A, and CAT-2B (system $\mathrm{y}^{+}$); $\mathrm{B}^{0,+}\left(\right.$ system $\left.\mathrm{B}^{0,+}\right)$; and ASCT1 (system ASC) are present in porcine MT. The objectives were to determine the presence of RNA transcripts for these transporters

Received January 17, 2004.

Accepted June 29, 2004.

Corresponding author: N. L. Trottier; e-mail: trottier@msu.edu.

*In part presented at the American Society of Animal Science National Meetings, Québec, Canada, July 21-25, 2002. and quantify their abundance during early (d 7) and peak (d 17) lactation.

Mammary biopsies from randomly selected lactating sows $(\mathrm{n}=3$ ) were performed, and tissue was rapidly flash-frozen in liquid nitrogen and stored at $-80^{\circ} \mathrm{C}$. Liver from a prepubertal gilt was collected following euthanasia and handled in same manner as MT. Liver was collected as a negative control for CAT-1 and CAT-2B and as a positive control for CAT-2A. Total RNA was isolated from liver and MT using TRIzol reagent (Invitrogen Life Technologies) following manufacturer's instructions as described in Weber et al. (2001).

Human CAT-1, CAT-2A, and CAT-2B cDNA probes were donated by E. Closs (Johannes Gutenberg University, Germany). A 400-bp CAT-2B-specific cDNA probe was developed from the region where human CAT-2A and CAT-2B differ (Closs et al., 1997). To confirm its identity to the human CAT-2B (GenBank Accession number U76369), the DNA fragment was sequenced using a dye-terminator fluorescent cycle sequencing technique and an ABI 3100 Genetic Analyzer (PerkinElmer Applied Biosystems, Foster City, CA). The sequenced fragment was then used to synthesize a ${ }^{32} \mathrm{P}$-labeled CAT2B cDNA probe. Porcine $\mathrm{B}^{0,+}$ and ASCT1 cDNA probes were developed by PCR using pooled cDNA from porcine MT as a template. The PCR primers were designed from the published human $\mathrm{B}^{0,+}$ (GenBank Accession number AF151978) and human ASCT1 (GenBank Accession numbers L14595 and L19444) cDNA sequences. Polymerase chain reaction was carried out in a RoboCycler Gradient 96 (Stratagene, La Jolla, CA) using Taq DNA polymerase as recommended by manufacturer (Invitrogen, Life Technologies). Resulting PCR amplification products were visualized as single bands of correct size using agarose gel electrophoresis (1.8\% gel), gel purified (Wizard PCR Preps DNA Purification System; Promega, Madison, WI) and ligated into the pGEM-T Easy cloning vector (Promega); recombinant plasmids were transformed into JM109 competent cells (Promega). Prior to radioactive labeling for Northern blot hybridizations, the cloned inserts were excised from purified plasmid DNA using EcoRI, gel purified (Wizard kit; Pro- 
mega) and visualized as single bright bands on $1.8 \%$ agarose checking gels stained with ethidium bromide. The 787 and 373 bp cDNA probes for $\mathrm{B}^{0,+}$ and ASCT1, respectively, were DNA sequenced in both directions to confirm identities using a dye-terminator fluorescent cycle sequencing technique and an ABI 3100 Genetic Analyzer (PerkinElmer Applied Biosystems), and the sequence information was deposited in GenBank (Accession numbers: AY375264 and AY375265).

The CAT-1, CAT-2A, CAT-2B, $\mathrm{B}^{0,+}$, and ASCT1 probes were validated by Northern blot analysis using duplicate aliquots of porcine liver and MT collected as described in Weber et al. (2001). Hybridizations were carried out for 18 to $24 \mathrm{~h}$ at $42^{\circ} \mathrm{C}$ using ${ }^{32} \mathrm{P}$-labeled cDNA probes (NEN Life Science Products, Inc., Boston, MA) generated by the random prime method (Feinberg and Vogelstein, 1983.). The blot was probed first with $\beta$-actin cDNA to verify equality of RNA loading across lanes, followed by CAT-1, CAT-2A, CAT-2B, B ${ }^{0,+}$, and ASCT1 cDNA with complete stripping of the blot between hybridizations. Nylon membranes (Amersham Biosciences, NJ) were then washed and exposed to BioMax MS film (Fisher Scientific, Pittsburgh, PA) for 24 to $240 \mathrm{~h}$ at $-80^{\circ} \mathrm{C}$ with an intensifying screen (Fisher Scientific).

Figure 1 shows Northern blot validations of CAT-1, CAT-2A, CAT-2B, $\mathrm{B}^{0,+}$ and ASCT1 cDNA probes. Human CAT-1 probe hybridized to a predominant transcript of expected size $(\sim 5.2 \mathrm{~kb})$ in MT. The CAT-1 also hybridized to a predominant transcript in liver tissue, which is in contrast to most species studied to date, but in agreement with Liu and Hatzoglou (1998), who also demonstrated the presence of CAT- 1 in rat liver. CAT-1 transcript presence in MT has also been demonstrated in sheep (Kiaei, M., M. P. Thompson, and M. R. Grigor, 1999, National Center for Biology Information, GenBank Accession number AF212146) and humans (Vékony et al., 2001). CAT-2A hybridized to a predominant transcript of expected size $(\sim 7.9 \mathrm{~kb})$ in porcine liver but not MT, which is consistent with other studies (Closs et al., 1993) demonstrating, to date, the specificity of CAT-2A for hepatic tissue only. In contrast to CAT-2A, the 400 bp CAT-2B probe hybridized to a single transcript in both liver and MT.

Porcine $\mathrm{B}^{0,+}$ probe hybridized to a predominant transcript in porcine MT, but not in liver. To date, $\mathrm{B}^{0,+}$ transcript presence in MT had been reported in humans only (Sloan and Mager, 1999). Porcine ASCT1 probe hybridized to a predominant transcript in both porcine liver and MT. Although ASCT1 expression has been demonstrated in a variety of tissues (Arriza et al., 1993), its expression in MT had not been reported to date. In summary, results demonstrate the presence of CAT-1, CAT$2 \mathrm{~B}, \mathrm{~B}^{0,+}$, and $\mathrm{ASCT} 1$ transcripts in lactating porcine MT.

\section{Lactating \\ Mammary Liver \\ $\begin{array}{llll}1 & 2 & 3 & 4\end{array}$}

$-\mathbf{5 . 2} \mathrm{kb}$

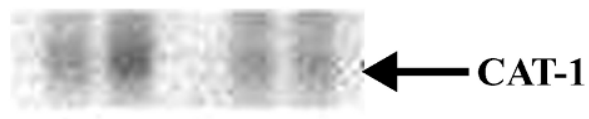

$-7.9 \mathrm{~kb}$

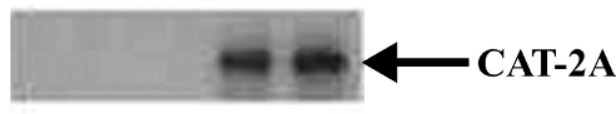

$-7.9 \mathrm{~kb}$

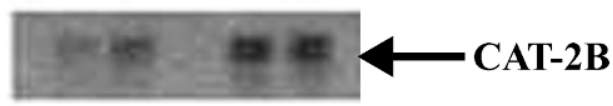

$-5.5 \mathrm{~kb}$

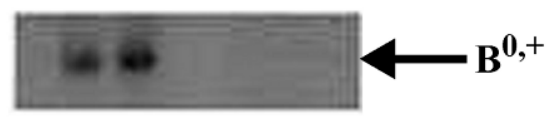

$-4.7 \mathrm{~kb}$

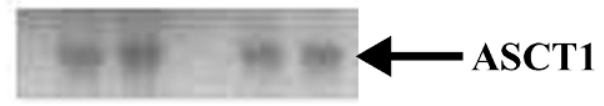

$-2.8 \mathrm{~kb}$

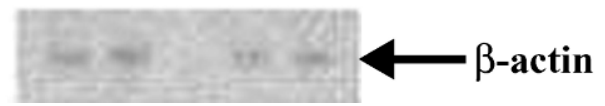

Figure 1. Northern blots of human CAT-1, CAT-2A, CAT-2B, and porcine $\mathrm{B}^{0,+}$ and ASCT1 in porcine mammary (Lanes 1 and 2) or liver tissue (Lanes 3 and 4). Blots were exposed to x-ray film for $120 \mathrm{~h}$ (CAT-1), $96 \mathrm{~h}$ (CAT-2A), $122 \mathrm{~h}$ (CAT-2B), $48 \mathrm{~h}\left(\mathrm{~B}^{0,+}\right), 24 \mathrm{~h}$ (ASCT1) or $240 \mathrm{~h}$ ( $\beta$-actin).

Transcript abundance on $\mathrm{d} 7$ and 17 of lactation of AA transporters CAT-1, CAT-2B, $\mathrm{B}^{0,+}$, and ASCT1 was determined by Northern blot analysis using the validated probes as described previously. Figure 2A suggests that $\mathrm{B}^{0,+}$ transcript abundance was lower on $\mathrm{d} 17 \mathrm{com}$ pared with $d 7$. No apparent change in transcript abundance was observed for CAT-1, CAT-2B, and ASCT1 (data not shown). Absolute quantification of $\mathrm{B}^{0,+} \mathrm{mRNA}$ abundance on $\mathrm{d} 7$ and 17 was also determined by realtime PCR. Porcine $\mathrm{B}^{0,+} \mathrm{cDNA}$ probe developed for Northern blot analysis was used as a standard template. Mammary tissue RNA from d 7 and 17 was converted into first-strand cDNA, and quantitative real-time RT-PCR was conducted as previously described (Coussens et al., 2003; Madsen et al., 2004) with $50 \mathrm{ng}$ of template cDNA and gene-specific primers designed using Primer Express (PerkinElmer Applied Biosystems). The $\mathrm{B}^{0,+}$ forward primer was 5' GGTGGTCCATTTTGGTCCATAT $3^{\prime}$, and reverse primer was 5' GTGATCGTTTCAATCG AAGCAA 3'. $\beta$-actin was used as the control gene in this system with forward primer 5' CTCCTTCCTGGGCAT GGA $3^{\prime}$ and reverse primer $5^{\prime}$ CGCACTTCATGATCGA GTTGA $3^{\prime}$. Five-point standard curves for $\mathrm{B}^{0,+}$ and $\beta$ actin were run on each plate and determined to be linear 
A

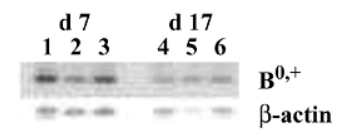

B

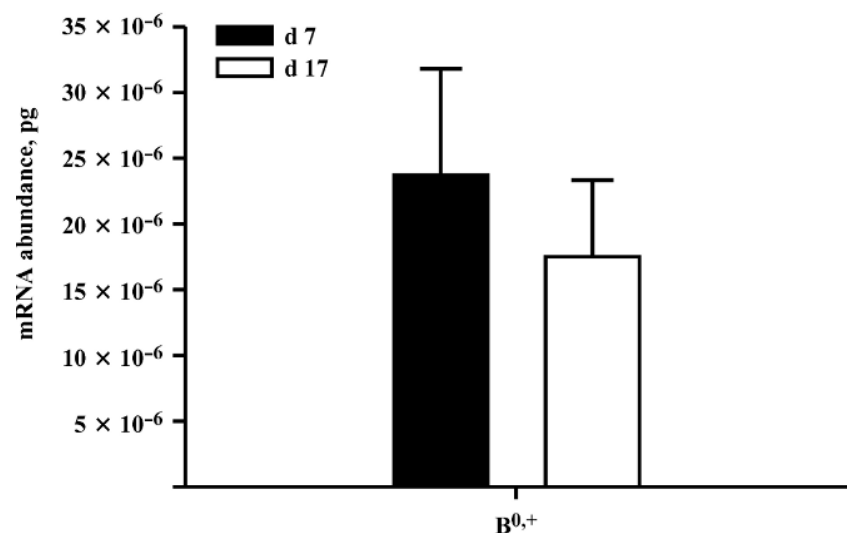

Figure 2. A) Northern blots of $\mathrm{B}^{0,+}$ at early (d 7) and peak (d 17) lactation in mammary tissue (MT) of 3 multiparous lactating sows. Lanes 1 and 4, Sow 1; Lanes 2 and 5, Sow 2; Lanes 3 and 6, Sow 3. Blots were exposed to x-ray film for $13 \mathrm{~h}\left(\mathrm{pB}^{0,+} \sim 5.3 \mathrm{~kb}\right)$ or $24 \mathrm{~h}(\mathrm{p} \beta$ actin $\sim 2.8 \mathrm{~kb}$ ). B) Porcine $\mathrm{B}^{0,+}$ transcript abundance in $50 \mathrm{ng}$ of cDNA as a function of day of lactation by using RT-PCR analysis. Bars represent means $\pm \mathrm{SE}$ from 3 multiparous lactating sows. Mean on d 17 tended to be lower than on d $7(P=0.08)$.

and parallel to each other, indicating similar reaction efficiency. All samples were run in triplicate. Three wells per plate had all reagents added except the cDNA template, which served as the negative control. All analyses were conducted using an ABI 7700 DNA sequence detection system (PerkinElmer Applied Biosystems). For each test amplification reaction, mean $\mathrm{B}^{0,+}$ expressions were normalized against $\beta$-actin (within sow and sample day) to account for differences between individual samples in RNA loading, cDNA synthesis efficiency, and amplification efficiency. Differences between means were detected using the MIXED procedure of SAS (1998). Figure 2B demonstrates that $\mathrm{B}^{0,+}$ transcript abundance tended $(P=$ $0.08)$ to decrease from early to peak lactation in porcine MT.

Considering that the protein synthetic capacity and AA uptake by porcine MT are higher during peak lactation compared with that of early lactation (Kim et al., 1999; Nielsen et al., 2002), an increase in transcript abundance of AA transporter proteins was expected. However, data presented herein on transcript abundance suggest that CAT-1, CAT-2B, and ASCT1 do not change with day of lactation and that $\mathrm{B}^{0,+}$ decreases from early to peak lactation. With the notion that mammary tissue is heterogeneous and composed of both stromal and epithelial cells, the possibility that expression of AA transporters differed between cell types cannot be refuted. We recognize that these results are limited because of the small sample size and that further research with larger sample size is critical to determine the relationship between AA transporter mRNA abundance and day of lactation. Nevertheless, as a whole, the data are novel and represent a gateway for the study of AA use and transport regulation in porcine MT at a molecular level.

\section{REFERENCES}

Arriza, J. L., M. P. Kavanaugh, W. A. Fairman, Y. Wu, G. H. Murdoch, R. A. North, and S. G. Amara. 1993. Cloning and expression of a human neutral amino acid transporter with structural similarity to the glutamate transporter gene family. J. Biol. Chem. 268:15329-15332.

Closs, E. I., L. M. Albritton, J. W. Kim, and J. M. Cunningham. 1993. Identification of a low affinity, high capacity transporter of cationic amino acids in mouse liver. J. Biol. Chem. 268:7538-7544.

Closs, E. I., P. Gräf, A. Habermeier, J. M. Cunningham, and U. Förstermann. 1997. Human cationic amino acid transporters hCAT1, hCAT-2A, and hCAT-2B: Three related carriers with distinct transport properties. Biochemistry 36:6462-6468.

Coussens, P. M., C. J. Colvin, G. J. M. Rosa, J. Pérez Laspiur, and M. D. Elftman. 2003. Evidence of a novel gene expression program in peripheral blood mononuclear cells from Mycobacterium avium subsp. paratuberculosis-infected cattle. Infect. Immun. 71:64876498.

Feinberg, A. P., and B. Vogelstein. 1983. A technique for radiolabeling DNA restriction endonuclease fragments to high specific activity. Anal. Biochem. 132:6-13.

Hurley, W. L., H. Wang, J. M. Bryson, and D. B. Shennan. 2000. Lysine uptake by mammary gland tissue from lactating sows. J. Anim. Sci. 78:391-395.

Jackson, S. C., J. M. Bryson, H. Wang, and W. L. Hurley. 2000. Cellular uptake of valine by lactating porcine mammary tissue. J. Anim. Sci. 78:2927-2932.

Kim, S. W., W. L. Hurley, I. K. Han, and R. A. Easter. 1999. Changes in tissue composition associated with mammary gland growth during lactation in sows. J. Anim. Sci. 77:2510-2516.

Liu, J., and M. Hatzoglou. 1998. Control of expression of the gene for the arginine transporter Cat-1 in rat liver cells by glucocorticoids and insulin. Amino Acids 15:321-337.

Madsen, S. A., L. Chang, M. Hickey, G. J. M. Rosa, P. M. Coussens, and J. L. Burton. 2004. Microarray analysis of gene expression in blood neutrophils of parturient cows. Physiol. Genomics 16:212221.

Meyer, J. S. 2001. Commentary: How is tumor growth controlled? Expression of L-type amino acid transporter 1 (LAT1) and 4F2 heavy chain $(4 \mathrm{~F} 2 \mathrm{hc})$ in liver tumor lesions of rat models. J. Surg. Oncol. 78:265-272.

Nielsen, T. T., N. L. Trottier, H. H. Stein, C. Bellaver, and R. A. Easter. 2002. The effect of litter size and day of lactation on amino acid uptake by the porcine mammary gland. J. Anim. Sci. 80:2402-2411.

SAS/STAT Software 8.1, 2000. SAS Inst., Inc., Cary, NC.

Sloan, J. L., and S. Mager. 1999. Cloning and functional expression of a human $\mathrm{Na}+$ and $\mathrm{Cl}$-dependent neutral and cationic amino acid transporter $\mathrm{B}^{0,+}$. J. Biol. Chem. 274:23740-23745.

Vékony, N., W. Sabine, J. P. Boissel, K. Gnauert, and E. I. Closs. 2001. Human cationic amino acid transporter hCAT-3 is preferentially expressed in peripheral tissues. Biochemistry 40:12387-12394.

Weber, P. S. D., S. A. Madsen, G. W. Smith, J. J. Ireland, and J. L. Burton. 2001. Pre-translational regulation of neutrophil L-selectin in glucocorticoids-challenged cattle. Vet. Immunol. Immunopathol. 6529:1-28. 